\section{(6) OPEN ACCESS}

\title{
Carving of non-asbestiform tremolite and the risk of lung cancer: a follow-up mortality study in a historical nephrite processing cohort
}

\author{
Hsiao-Yu Yang, ${ }^{1,2}$ Ruei-Hao Shie, ${ }^{3}$ Pau-Chung Chen ${ }^{4,5,6}$
}

\begin{abstract}
'Department of Occupationa Medicine, Buddhist Tzu Chi General Hospital, Hualien, Taiwan

${ }^{2}$ School of Medicine, Tzu Chi University, Hualien, Taiwan ${ }^{3}$ Green Energy and

Environmental Research Laboratories, Industrial

Technology Research Institute, Hsinchu, Taiwan

${ }^{4}$ Institute of Occupational Medicine and Industrial Hygiene, National Taiwan University College of Public Health, Taipei, Taiwan ${ }^{5}$ Department of Public Health, National Taiwan University College of Public Health, Taipei, Taiwan

${ }^{6}$ Department of Environmental and Occupational Medicine, National Taiwan University Hospital and National Taiwan University College of Medicine, Taipei, Taiwan
\end{abstract}

\section{Correspondence to} Dr Pau-Chung Chen, Institute of Occupational Medicine and Industrial Hygiene, National Taiwan University College of Public Health, No. 17 Xuzhou Road, Taipei 100, Taiwan; pchen@ntu.edu.tw

Received 28 January 2013 Revised 12 August 2013 Accepted 27 August 2013 Published Online First 18 September 2013

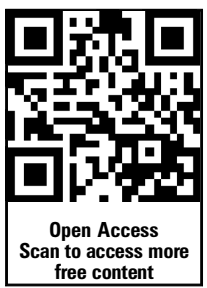

\footnotetext{
To cite: Yang $\mathrm{H}-\mathrm{Y}$, Shie R-H, Chen P-C. Occup Environ Med 2013;70: 852-857.
}

\begin{abstract}
Objectives The health risks associated with exposure to non-asbestiform asbestos minerals, including nephrite, are unclear. In 1965 nephrite processing began in the town of Fengtian in Taiwan, and the majority of inhabitants were involved in the industry from 1970 until 1980. The objectives of this study were to examine lung cancer deaths and assess the carcinogenic effects of nephrite carving.

Methods We studied mortality due to lung cancer (ICD-9 code 162 for cancers of the trachea, bronchus and lung) from 1979 to 2011. We calculated the standardised mortality ratio (SMR) for lung cancer using the age- and sex-specific cancer mortality rates in eastern Taiwan as the standard rates. Air samples, bulk samples and a surface sample were analysed.

Results Nephrite is a non-asbestiform asbestos mineral composed of microcrystalline tremolite. During nephrite processing, in personal air samples the average

\section{What this paper adds}

- It is unclear whether or not there is a risk of cancer when workers carve non-asbestiform minerals.

- Nephrite is a non-asbestiform asbestos mineral composed of microcrystalline tremolite asbestos, so carving will release intact asbestiform tremolite fibres into the air.

- A significantly increased risk of lung cancer was observed in this study of the inhabitants of Fengtian used as a historical cohort sharing a given exposure due to the carving of nephrite.

- As the carving of nephrite may increase the risk of lung cancer, appropriate medical monitoring is warranted for workers exposed to similar materials.
\end{abstract} concentration of elongated mineral particles with the morphological characteristics of asbestos fibres was $1.4 \mathrm{f} / \mathrm{cm}^{3}$, with rough grinding generating the highest concentrations $\left(4.7 \mathrm{f} / \mathrm{cm}^{3}\right)$. Transmission electron microscopy (TEM) confirmed that the air samples contained intact asbestiform tremolite fibres. The ambient air samples and the wipe sample indicated paraoccupational contamination. The crude mortality rates for lung cancer were higher in Fengtian than in Taiwan for all age groups and both genders. The SMR for lung cancer was 1.28 (95\% Cl 1.12 to 1.45$)$. Conclusions Nephrite carving may increase the risk of lung cancer. Appropriate medical monitoring is warranted for workers who are exposed to similar materials.

Asbestos has been used extensively since the 19th century. The generic term 'asbestos' is used to describe a group of minerals that, when crushed, break into fibres rather than dust. ${ }^{1}$ Its fibrous structure and chemical resistance characteristics have resulted in the extensive use of asbestos in many commercial products. However, not all asbestos minerals have typical fibrous structures; some can exist in compacted masses and are recognised as non-asbestiform asbestos minerals. Non-asbestiform asbestos minerals are common in the stone and jewellery industries, and carving them can release airborne asbestos fibres. ${ }^{2}$ Although asbestiform asbestos minerals are well known carcinogens, ${ }^{3}$ a recent systematic review by the US National Institute for Occupational Safety and Health
(NIOSH) stated that the health hazards associated with exposure to non-asbestiform asbestos minerals remain to be elucidated. ${ }^{4}$

Nephrite is a non-asbestiform asbestos mineral ${ }^{5}$ which in Chinese society has been made into jade decorations since ancient times. Yang et $a l^{6}$ conducted a survey of the industry in Taiwan. They reported that nephrite is composed of microcrystalline tremolite asbestos with a high percentage of asbestiform fibres and that nephrite workers have a dose-dependent increased risk of pulmonary fibrosis. Although nephrite may release asbestos fibres when it is broken, no epidemiological study has explored the carcinogenic effects of processing nephrite.

Fengtian is a small town in Hualien County, Taiwan, with the only nephrite mines in the country. In Neolithic times, nephrite was produced in Fengtian to make jade artefacts for residents along the southern and eastern coasts of the South China Sea. ${ }^{8}$ According to a government report, nephrite was re-discovered in Fengtian in 1961, and the nephrite jade processing industry began in 1965. ${ }^{9}$ Between 1966 and 1974, Fengtian became the main location for nephrite mining in the world. ${ }^{10}$ A panel discussion with master nephrite workers and inhabitants in Fengtian in the 1970s indicated that there were more than 80 nephrite workshops in the small town. The industry was family based, and the majority of Fengtian inhabitants, particularly working-age women, were 
involved in nephrite processing. The nephrite mining and the nephrite jade processing industries rapidly declined after 1980 . This study used the inhabitants of Fengtian as a historical cohort that shared a given exposure during the act of carving nephrite during that period. Because Fengtian is the only place where nephrite is produced in Taiwan, we studied mortality associated with lung cancer in Fengtian to determine whether carving nephrite increases the risk of lung cancer. Air and bulk samples were collected, a field survey was carried out and questionnaires were analysed.

\section{METHODS}

\section{Reconstruction of exposure history in the nephrite industry}

We determined annual nephrite production from mining in Fengtian from data supplied by the Taiwan Ministry of Economic Affairs. ${ }^{10}$ Because nephrite factories are small businesses and typically use traditional and basic equipment, there have been no significant changes in the methods used for carving. We included data on nephrite workers published in our previous study to show the character of the industry. ${ }^{6}$ Before field sampling, we walked through workplaces and recorded the data on the environment, processing procedures, materials used in each procedure, potential emission sources, final products and waste management procedures. A nephrite worker typically carries out several tasks (procedures), including cutting, rough grinding, fine grinding and polishing. A panel discussion was held to determine the sampling strategy. Bulk sampling, air sampling and surface sampling were carried out in a traditional nephrite-processing workshop and then analysed in accredited laboratories that comply with the international quality assurance standard promulgated by the National Voluntary Laboratory Accreditation Program (NVLAP).

\section{Air sample analyses}

Both integrated personal air sampling and continuous area air sampling were carried out. Four consecutive personal air samples for each procedure required to create a nephrite jade ornament were collected separately and analysed to determine the concentrations to which the worker was exposed. A personal sampling device was attached to the worker's collar. One continuous area air sampling by a pump in a fixed position near the door was initiated at the beginning of a work cycle and ran until the cycle was completed. A sampling rate of $3.0 \mathrm{~L} / \mathrm{min}$ and a sampling time of $20 \mathrm{~min}$ were used, which took into account the potential for a low concentration of fibres during wet manufacturing methods and prevented the filters from becoming damp in case this influenced collecting efficiency. The sampling strategy was in accordance with the Occupational Safety and Health Administration (OSHA) method ID-160-regulated minimum sampling volume of 25 L. $^{11}$ Air sampling was performed by industrial hygienists and occupational physicians at a traditional nephrite-processing workshop in Hualien on 23 August 2010. Two field blank samples were used for this set of analyses. The field samples and field blank samples were then transported to a certified laboratory for analysis.

The bulk nephrite samples were analysed using polarised light microscopy (PLM) and energy dispersive X-ray (EDX) spectroscopy. Mineral identification was performed using the EPA-600/ R93-116 method. ${ }^{12}$ The air samples were first analysed for asbestos using phase-contrast microscopy (PCM) according to the counting rules of NIOSH method 7400 ' $^{\prime 13}$ and then analysed using TEM with selected area electron diffraction (SAED) according to NIOSH method 7402 to identify the presence of asbestos fibres and the dimensional properties and elemental composition of the fibres. ${ }^{14}$ Because nephrite jade workers repeat the same tasks numerous times during a given work shift, we assumed there would be a steady level of exposure during the unsampled period. Under the assumption that exposure during the unsampled period was identical to that during the sampled period, a time-weighted average concentration was calculated. The concentration $(\mathrm{Ci})$ and the corresponding sample time (Ti) for each consecutive sample were time weighted $(\mathrm{Ci} \times \mathrm{Ti})$ and averaged by dividing the time-weighted value by the total sample time. The results were expressed as an $8 \mathrm{~h}$ work shift time-weighted average concentration. This value was then compared with the permissible exposure level. To evaluate surface contamination, we used a mixed cellulose ester filter to obtain a $100 \mathrm{~cm}^{2}$ surface sample from a lampshade on a worktable. The wipe sample was stored in a conductive filter transport case and transported to a certified laboratory. The sample was then examined using PCM, a Walton-Beckett graticule and an HSE/NPL phase-shift test slide, and analysed according to the counting rules of NIOSH analytical method 7400 'A'. ${ }^{13}$ For our purposes, an 'asbestiform asbestos fibre' was defined as an intact, elongated crystalline mineral with edges that ran parallel along the crystal edge. In contrast, a 'cleavage fragment' was defined as an elongated mineral particle with only a quasicrystalline construction or edges that showed breakage, weathering, undulations, or damage due to stress.

\section{Statistical analysis}

Data on mortality rates from 1979 to the end of 2011 were obtained from the Taiwan National Mortality Registry Database. ${ }^{15}$ There were 21022 inhabitants in Fengtian at the beginning of the follow-up period and 17321 at the end. The 5 -year mortality rates and age-specific cumulative mortality for lung cancer (ICD-9 code 162 for cancers of the trachea, bronchus and lung) were calculated. We determined the standardised mortality ratio (SMR) for lung cancer using an indirect standardisation method with a 10-year lag in the measurement of the association using the SMR to compare the mortality rate in the exposed population to that in the unexposed population. One general concern in using the SMR to measure this association is the appropriateness of the comparison population selected. ${ }^{16}$ The island of Taiwan is geologically separated into western and eastern areas by high mountains, and Fengtian is located in eastern Taiwan, which is a rural area. Thus, the mortality rates in this region may be different from the national mortality rates. In calculating the SMR, we used the age- and sex-specific cancer mortality rates in eastern Taiwan as the standard rates. Because the mortality rates are generally influenced by the age distribution of a given population, we also provided the age-standardised mortality rates for lung cancer adjusted to the world standard population, as reported by the World Health Organization for the year 2000. Statistical calculations were performed using SAS V.9.2 software (SAS Institute, Cary, North Carolina, USA).

\section{RESULTS}

Annual nephrite production figures and the age-standardised mortality rates for lung cancer in Fengtian are given in figure 1. The crude mortality rates for lung cancers were higher in Fengtian than in Taiwan for all age groups and both genders (figure 2). The SMR for lung cancer in Fengtian was 1.28 (95\% CI 1.12 to 1.45 ). The 5 -year lung cancer mortality rates in Fengtian from 1979 to 2008 are summarised in table 1 . The data gathered in our previous study of 53 nephrite workers were examined to help us understand the industry. The nephrite industry is typically a microenterprise, and $92.5 \%$ of workplaces 
Figure 1 Annual production of nephrite and the age-standardised mortality rates for lung cancer in Fengtian: nephrite mine production (solid line), male rates (black bar) and female rates (white bar).

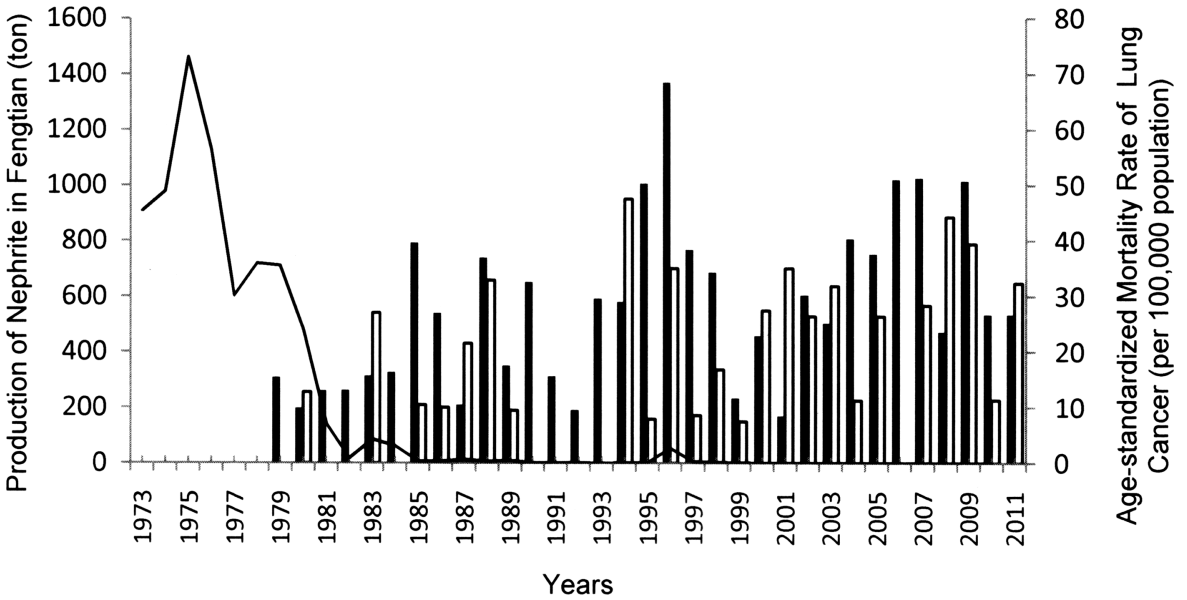

had fewer than nine workers. In addition, 90.6\% of the workers worked in their own home or a canopied yard. Most workers were involved in all processing procedures, although a significantly higher proportion $(74.1 \%)$ of the cutting procedures were performed by male workers $(p<0.05)$, with $26.1 \%$ of the female workers involved in cutting, $82.6 \%$ in grinding and $87.0 \%$ in polishing.

Samples of the three major types of bulk nephrite were ground and prepared using series E HD 1.605 refractive index liquids and examined under PLM combined with central stop dispersion staining. The nephrite samples were composed of asbestiform tremolite-actinolite in compact crystalline masses. EDX analysis of the bulk sample and SAED of the air samples confirmed that the air particles originated from the processed bulk sample without contamination by other minerals. For the personal air sample obtained from a nephrite worker, the $8 \mathrm{~h}$ time-weighted average concentration of elongated mineral particles with the morphological characteristics of asbestos fibres was $1.4 \mathrm{f} / \mathrm{cm}^{3}$. Rough grinding generated the highest concentration of fibres $\left(4.7 \mathrm{f} / \mathrm{cm}^{3}\right)$, while the concentration of asbestos in ambient air was $0.11 \mathrm{f} / \mathrm{cm}^{3}$. The NIOSH light microscopic criteria fibre density of the wipe sample was

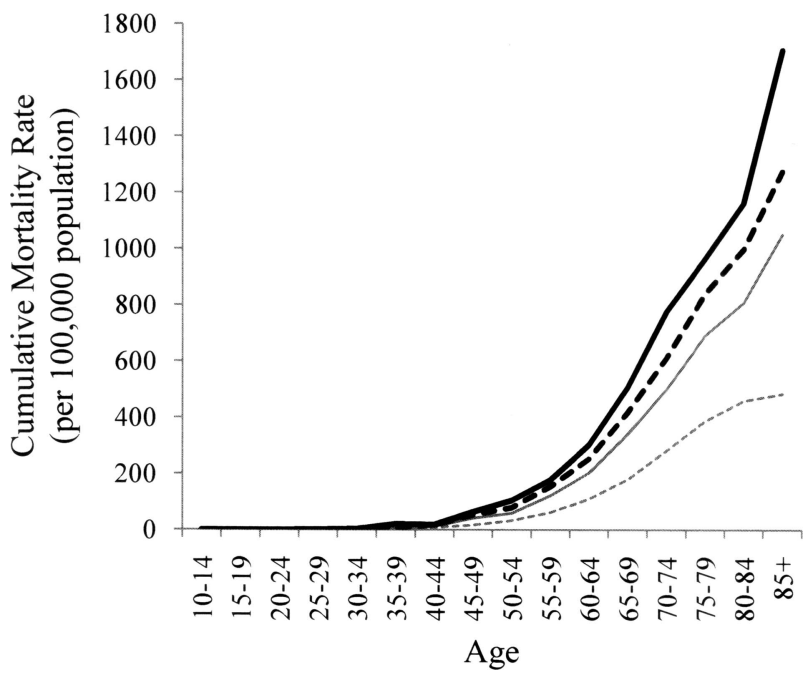

Figure 2 Age-specific cumulative mortality rates from lung cancer in Fengtian and Taiwan. Age-specific curves are shown for four groups: females in Fengtian (bold solid line), females in Taiwan (bold broken line), males in Fengtian (fine solid line) and males in Taiwan (fine broken line).
$48.4 \mathrm{f} / \mathrm{mm}^{2}$. TEM confirmed that the airborne asbestos fibres identified by the PCM method were tremolite with both asbestiform asbestos fibres (figure 3A) and cleavage fragments (figure 3B). According to TEM method 7402, the $8 \mathrm{~h}$ time-weighted average concentration of asbestos fibres greater than $0.5 \mu \mathrm{m}$ was $9.51 \mathrm{f} /$ $\mathrm{cm}^{3}$, and the concentration of asbestos fibres greater than $5.0 \mu \mathrm{m}$ was $1.04 \mathrm{f} / \mathrm{cm}^{3}$ (table 2).

\section{DISCUSSION}

Nephrite is a non-asbestiform tremolite mineral. Although nephrite exists in compact masses, the carving of nephrite releases asbestos fibres into the air when the nephrite is ground or broken. The concentration of asbestos fibres found in our study exceeded the OSHA permissible exposure limit. The ambient air samples and the wipe sample indicate possible paraoccupational contamination. A significantly increased risk of lung cancer was observed in Fengtian in the 33-year follow-up mortality study. To the best of our knowledge, this is the first epidemiological study to provide field sampling data and asbestiform asbestos mineral.

In theory, this is an ecological study exploring the risk of lung cancer in a geographically defined population in Fengtian. The association between the production of nephrite decorations in Fengtian and the subsequently increased mortality rate may not accurately reflect a causal relationship and there might be ecological bias. Therefore, the results should be interpreted with caution. Yang et $a l^{6}$ have reported that the destruction of nephrite can release asbestiform fibres and that nephrite carvers have an increased risk of pulmonary fibrosis. This study further suggests that the carving of nephrite may also increase the risk of lung cancer.

Because the nephrite industry is family-based and no past exposure measurement data are available, we conducted the survey and field sampling at a traditional family-based workshop established in 1974. The manufacturing procedures, tools and conditions in this workshop are representative of the nephrite industry, and similar to those during the historical period of interest. The combined use of light microscopy and electron microscopy to evaluate air samples and bulk samples shows that nephrite consists of microcrystalline tremolite asbestos with a high percentage of asbestiform fibres and that the breaking of concreted nephrite ore releases asbestiform tremolite asbestos fibres into the air. Analysis of the personal air samples obtained from the nephrite workers revealed that the concentration of elongated mineral particles with the morphological explore the possible carcinogenic effect of carving a non- 
Table 1 Five-year lung cancer mortality rate in Fengtian from 1979 to 2008

\begin{tabular}{|c|c|c|c|c|c|c|c|c|c|}
\hline \multirow[b]{2}{*}{ Years } & \multicolumn{3}{|l|}{ Male } & \multicolumn{3}{|l|}{ Female } & \multicolumn{3}{|l|}{ All } \\
\hline & Population & Cases & CR & Population & Cases & CR & Population & Cases & CR \\
\hline 1979-1983 & 11980 & 14 & 116.9 & 8893 & 3 & 33.7 & 20837 & 17 & 81.6 \\
\hline 1984-1988 & 11256 & 21 & 186.6 & 8729 & 7 & 80.2 & 19985 & 28 & 140.1 \\
\hline 1989-1993 & 10519 & 14 & 133.1 & 8183 & 1 & 12.2 & 18702 & 15 & 80.2 \\
\hline 1994-1998 & 10358 & 36 & 347.6 & 8175 & 12 & 146.8 & 18533 & 48 & 259.0 \\
\hline 1999-2003 & 9997 & 20 & 200.1 & 7949 & 18 & 226.4 & 17937 & 38 & 211.9 \\
\hline 2004-2008 & 9830 & 42 & 427.3 & 8041 & 16 & 199.0 & 17871 & 58 & 324.5 \\
\hline
\end{tabular}

characteristics of asbestos fibres determined according to the NIOSH 7400 PCM method was $1.4 \mathrm{f} / \mathrm{cm}^{3}$. This value exceeded the OSHA permissible exposure limit of $0.1 \mathrm{f} / \mathrm{cm}^{3}$. The results obtained using the NIOSH 7402 TEM method demonstrated that $11 \%$ of the examined fibres met the PCM definition of an asbestos fibre (aspect ratio greater than 3:1 and longer than $5 \mu \mathrm{m})$. According to the Helsinki Criteria, which is a consensus report from the International Expert Meeting on Asbestos, Asbestosis, and Cancer, one fibre per cubic centimetre per year (fibre-year) of cumulative exposure is estimated to increase the relative risk of lung cancer by $0.5-4 \% .{ }^{17}$ Using the upper boundary of this range, we estimated that 10 years of exposure to the asbestos concentration of $1.4 \mathrm{f} / \mathrm{cm}^{3}$, obtained from carving nephrite, increases the risk of lung cancer by 1.56 -fold when compared with the non-exposed population. According to European Commission guidance for the diagnosis of lung cancer following the inhalation of asbestos dust, 20 years of exposure is sufficient to cause lung cancer; the lag-time we observed between the peak production period of nephrite and the increased age-standardised mortality rate from lung cancer was longer than the minimum induction period of 15 years. ${ }^{18}$ The high asbestos fibre density in the surface sample suggested that paraoccupational exposure to asbestos may occur from such deposits. The typical air concentrations of asbestos fibres in ambient air are in the range of $0.00001-0.0001 \mathrm{f} / \mathrm{cm}^{3},{ }^{16} 19$ although our environmental ambient air asbestos sample contained $0.11 \mathrm{f} / \mathrm{cm}^{3}$, which also exceeded the OSHA permissible exposure limit. Because nephrite was typically processed in family-based workshops and because there was no distinction between the work place and the home, family members who did not process nephrite may also have been exposed to asbestos from paraoccupational contamination. The results suggest that residents living close to nephrite manufacturing sites may have been exposed to higher levels of airborne asbestos than the levels in the general ambient air. Therefore, the processing of nephrite likely contributed significantly to the increased risk of lung cancer in Fengtian. In addition, although our samples primarily involved wet procedures, the concentration of asbestos from nephrite processing might be higher with dry techniques.

Cigarette smoking increases the risk of lung cancer. ${ }^{20}$ Thus, to assess the potential confounding of results due to cigarette smoking, we determined the prevalence of cigarette smoking from a Taiwan national survey of adult smoking behaviour conducted by the Bureau of Health Promotion of the Department of Health in 2008. ${ }^{21}$ The survey stratified 16892 randomly sampled subjects from 25 counties/cities in Taiwan who were over the age of 18 years, and showed that the prevalence of current smoking was $21.8 \%$ and $21.9 \%$ in Hualien County and Taiwan, respectively. Thus, the increased risk of lung cancer in Fengtian was likely independent of smoking status.

Asbestos was mined in Fengtian between 1938 and $1985 .^{22}$ Although the level of production was low and asbestos mining has since stopped, we should consider the possibility of environmental contamination from natural weathering and erosion processes that may release asbestos fibres into the air. These mines are located in a remote mountainous area that is about 15 kilometers of distance on the opposite side of Fengtian, and traversing the distance requires 2-3 hours by car. Thus, as any released fibres were unlikely to travel the long distance to Fengtian, we conservatively estimate that these mining operations did not contribute to the increased risk of lung cancer.

Mesothelioma is an important index disease for asbestos exposure. ${ }^{1}$ However, we found no deaths from cancer of the pleura in the mortality registry. There are some possible reasons for this finding. Mesothelioma is a very rare cancer. Based on the general mortality rates in Taiwan, the expected number of deaths from mesothelioma in Fengtian was 0.96. We conservatively hypothesise that the population in Fengtian is too small to detect this effect. In Taiwan, the ICD-9 system is still used in the mortality registry. Misclassification of mesothelioma is a common problem in the ICD-9 system, which did not have a specific diagnostic category until the 10th review. Fengtian is

Figure 3 Particles from the air sample viewed by transmission electron microscopy, demonstrating both asbestiform fibres and cleavage fragments. (A) An intact asbestiform asbestos fibre. (B) A cleavage fragment. The elongated mineral particle is identified as a cleavage fragment because of non-parallel edges.
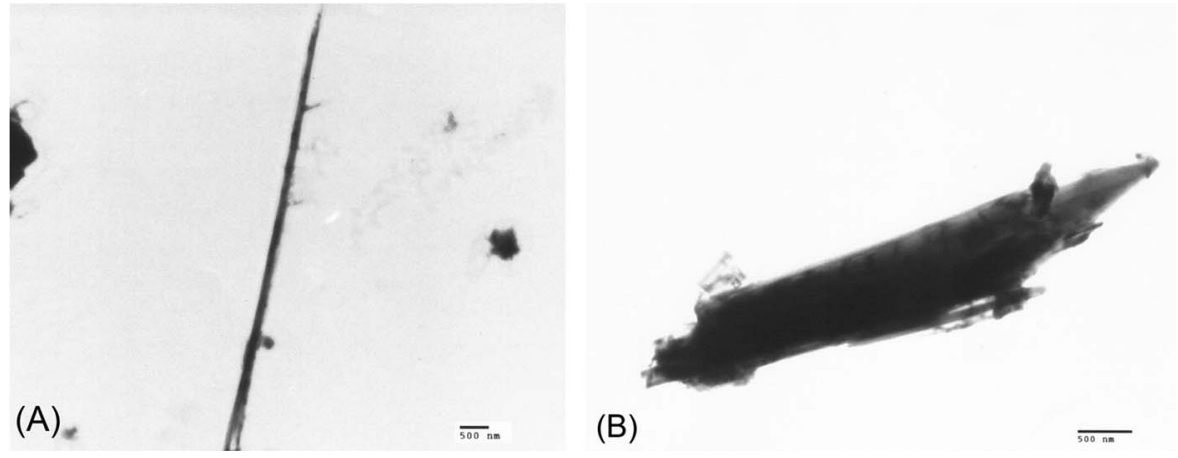
Table 2 Asbestos fibre concentrations at a nephrite processing factory analysed by PCM and TEM

\begin{tabular}{|c|c|c|c|c|c|c|c|}
\hline \multirow[b]{2}{*}{ Location } & \multirow[b]{2}{*}{ Procedure } & \multirow[b]{2}{*}{ Sample time (min) } & \multirow[b]{2}{*}{ Air volume (L) } & \multicolumn{3}{|c|}{ Concentration $\left(\mathrm{f} / \mathrm{cm}^{3}\right)$} & \multirow[b]{2}{*}{ Asbestos type } \\
\hline & & & & PCM & $\begin{array}{l}\text { TEM } \\
\text { Length } \geq 0.5 \mu \mathrm{m}\end{array}$ & $\begin{array}{l}\text { TEM } \\
\text { Length } \geq 5 \mu \mathrm{m}\end{array}$ & \\
\hline \multirow[t]{4}{*}{ Worker } & Cutting & 20 & 60.084 & 0.44 & 12.1 & 1.0 & Tremolite, actinolite \\
\hline & Rough grinding & 20 & 60.084 & 4.70 & 24 & 2.9 & Tremolite, actinolite \\
\hline & Fine grinding & 20 & 60.084 & 0.18 & 0.098 & 0.05 & Tremolite \\
\hline & Polishing & 16.1 & 48.368 & $<0.059$ & $<0.062$ & $<0.062$ & None detected \\
\hline Environment & Ambient air & 76 & 225.963 & 0.11 & 2.1 & 0.34 & Tremolite \\
\hline
\end{tabular}

located in a rural area of eastern Taiwan, where the level of medical diagnosis used to be poor, and so mesothelioma might be misdiagnosed as lung cancer and therefore under-reported.

The statement that non-asbestiform minerals pose no health risks remains to be elucidated. ${ }^{4}$ Epidemiological studies investigating the health effects of non-asbestiform tremolite are limited. In an animal study, Davis administered intraperitoneal injections of tremolite to rats, and three of the asbestiform samples induced mesothelioma in $100 \%, 97 \%$ and $97 \%$ of the challenged animals. ${ }^{23}$ Injection of one predominantly non-asbestiform sample containing a small amount of asbestiform tremolite, led to the development of mesothelioma in $67 \%$ of the animals, whereas injection of two non-asbestiform tremolite samples resulted in mesothelioma in 12\% and 5\% of the animals. Asbestiform tremolite is little used in industry, and so most studies concerning its health risks have focused on the domestic use of whitewash in Turkey $^{24-26}$ and Greece, ${ }^{27} 28$ environmental exposure near stone quarries in Italy $^{29}$ and occupational exposure to tremolitecontaminated talc in New York. In a study conducted in St. Lawrence County, New York, talc deposits were found to contain 37-59\% non-asbestiform tremolite. ${ }^{30}$ Gamble conducted a nested case-control study in a cohort of New York talc workers but did not find an increased risk of lung cancer after excluding cases with less than 20 years of latency and controlling for smoking. ${ }^{31}$ Honda et al followed lung cancer mortality in a New York talc cohort between 1950 and 1989 and found that the SMR for lung cancer was 1.31 (95\% CI 1.14 to 1.50 ) using the regional general population cancer mortality rates as the standard rates. ${ }^{32}$ However, the authors suggested that the increased risk may have been due to confounding factors such as smoking or other unidentified risk factors. Finkelstein followed the New York talc cohort and observed six deaths due to mesothelioma after 1994. ${ }^{33} \mathrm{He}$ also reported an excess incidence of mesothelioma in this cohort during 1990-2007. Our study provides further evidence of a possible carcinogenetic effect of the processing of nonasbestiform tremolite jade.

\section{Limitations}

There may be important physicochemical differences between asbestiform and non-asbestiform elongated particles. However, we must mention that neither NIOSH method 7400 nor NIOSH method 7402 is capable of distinguishing between the proportion of asbestiform fibres and non-asbestiform cleavage fragments.

\section{CONCLUSION}

Workers carving nephrite will inhale asbestos fibres, which may increase their risk of lung cancer. Appropriate medical monitoring is warranted for workers who are exposed to similar materials.
Acknowledgements The authors gratefully acknowledge the Bureau of Health Promotion, Department of Health, Taiwan, for providing the death certificate data.

Contributors $\mathrm{H}-\mathrm{YY}$ conducted the literature review, and designed and implemented the study. R-HS contributed to the walk-through survey, sampling strategies and risk assessment. P-CC contributed to quality assurance and control.

Funding The study was supported by National Science Council (NSC) grant no. 100-2314-B-320-002-MY3.

\section{Competing interests None.}

Provenance and peer review Not commissioned; externally peer reviewed.

Open Access This is an Open Access article distributed in accordance with the Creative Commons Attribution Non Commercial (CC BY-NC 3.0) license, which permits others to distribute, remix, adapt, build upon this work non-commercially, and license their derivative works on different terms, provided the original work is properly cited and the use is non-commercial. See: http://creativecommons.org/ licenses/by-nc/3.0/

\section{REFERENCES}

1 Murphy RL, Becklake MR, Brooks SM, et al. The diagnosis of nonmalignant diseases related to asbestos. Am Rev Respir Dis 1986;134:363-8.

2 Harper M, Lee EG, Doorn SS, et al. Differentiating non-asbestiform amphibole and amphibole asbestos by size characteristics. J Occup Environ Hyg 2008:5:761-70.

3 International Agency for Research on Cancer. IARC monographs on the evaluation of carcinogenic risks to humans, Vol 14: Asbestos. Lyon, France: IARC, 1998. http:// monographs.iarc.fr/ENG/Monographs/vol14/volume14.pdf (accessed 22 May 2013).

4 National Institute for Occupational Safety and Health. Asbestos fibers and other elongated mineral particles: state of the science and roadmap for research. NIOSH, 2011. http://www.cdc.gov/niosh/docs/2011-159/pdfs/2011-159.pdf (accessed 22 May 2013).

5 Bailey KF, Kelse J, Wylie AG, et al. The asbestiform and nonasbestiform mineral growth habit and their relationship to cancer studies. 2003 April. http://www.cdc. gov/niosh/docket/archive/pdfs/NIOSH-099A/0099A-030104-Pictorialpresentation.pdf (accessed 22 May 2013).

6 Yang HY, Shie RH, Chen PC. Pulmonary fibrosis in workers exposed to non-asbestiform tremolite asbestos minerals. Epidemiology 2013;24:143-9.

7 Ilgren EB. The biology of cleavage fragments: a brief synthesis and analysis of current knowledge. Indoor Built Environ 2004;13:343-56.

8 Hung $\mathrm{HC}$, lizuka $Y$, Bellwood $\mathrm{P}$, et al. Ancient jades map 3,000 years of prehistoric exchange in Southeast Asia. Proc Natl Acad Sci USA 2007;104:19745-50.

9 Huang WG, Lin MY, Su WL, et al. eds. Discovery of Taiwan jade. Taipei, Taiwan: Administration in Ministry of Economic Affairs, 2008. (in Chinese)

10 Ministry of Economic Affairs. Mineral statistic yearbook of Taiwan area, the Republic of China. Taipei, Taiwan: Ministry of Economic Affairs, 1962-2007. (in Chinese)

11 Occupational Safety \& Health Administration. Sampling and Analytical Methods No. ID160: Asbestos in air. http://www.osha.gov/dts/sltc/methods/inorganic/id160/id160. html (accessed 23 May 2013).

12 Perkins RL, Harvey BW. Method for the determination of asbestos in bulk building materials. EPA/600/R93-116. Washinton, DC: U.S. Environmental Protection Agency, 1993.

13 US National Institute for Occupational Safety and Health. Asbestos and other Fibers by PCM-Method 7400. http://www.cdc.gov/niosh/docs/2003-154/pdfs/7400.pdf (accessed 23 May 2013).

14 US National Institute for Occupational Safety and Health. Asbestos by TEM-Method 7402. http://www.cdc.gov/niosh/docs/2003-154/pdfs/7402.pdf (accessed 23 May 2013).

15 Hsieh GY, Chen PC, Wang JD. Verification and correction of error for death registration data of the department of health R.O.C. between 1980 and 1997. Taiwan J Public Health 2002;21:329-38. (in Chinese) 
16 International Agency for Research on Cancer. IARC monographs on the evaluation of carcinogenic risks to humans volume $100 \mathrm{C}$ (2012): a review of human carcinogens: arsenic, metal, fiber, and dusts. http://monographs.iarc.fr/ENG/ Monographs/vol100C/index.php (accessed 23 May 2013).

17 Anonymous. Asbestos, asbestosis, and cancer: the Helsinki criteria for diagnosis and attribution. Scand J Work Environ Health 1997;23:311-6.

18 Henderson DW, Rodelsperger K, Woitowitz HJ, et al. After Helsinki: a multidisciplinary review of the relationship between asbestos exposure and lung cancer, with emphasis on studies published during 1997-2004. Pathology 2004:36:517-50.

19 Agency for Toxic Substances \& Diseases Registry. What is asbestos? http://www. atsdr.cdc.gov/asbestos/more_about_asbestos/what_is_asbestos/ (accessed 23 May 2013).

20 Olsen AM, Ochsner A. Relationship of smoking to carcinoma. Dis Chest 1968:54:191.

21 Taiwan Bureau of Health Promotion. Adult Smoking Behavior Survey in 2008. http://olap.bhp.doh.gov.tw/ (accessed 8 September 2013).

22 Yang HY, Wang JD, Chen PC, et al. Pleural plaque related to asbestos mining in Taiwan. J Formos Med Assoc 2010;109:928-33.

23 Davis JM, Addison J, Mclntosh C, et al. Variations in the carcinogenicity of tremolite dust samples of differing morphology. Ann N Y Acad Sci 1991;643:473-90.

24 Yazicioglu S, Ilcayto R, Balci K, et al. Pleural calcification, pleural mesotheliomas, and bronchial cancers caused by tremolite dust. Thorax 1980;35:564-9.
25 Coplu L, Dumortier P, Demir AU, et al. An epidemiological study in an Anatolian village in Turkey environmentally exposed to tremolite asbestos. J Environ Pathol Toxicol Oncol 1996:15:177-82.

26 Baris Yl, Bilir N, Artvinli M, et al. An epidemiological study in an Anatolian village environmentally exposed to tremolite asbestos. Br J Ind Med 1988;45:838-40.

27 Langer AM, Nolan RP, Constantopoulos SH, et al. Association of Metsovo lung and pleural mesothelioma with exposure to tremolite-containing whitewash. Lancet 1987;1:965-7.

28 Constantopoulos SH, Theodoracopoulos P, Dascalopoulos G, et al. Metsovo lung outside Metsovo. Endemic pleural calcifications in the ophiolite belts of Greece. Chest 1991;99:1158-61

29 Paoletti L, Batisti D, Bruno C, et al. Unusually high incidence of malignant pleura mesothelioma in a town of eastern Sicily: an epidemiological and environmental study. Arch Environ Health 2000:55:392-8.

30 Dement JM, Zumwalde RD, Gamble JF, et al. Occupational exposure to talc containing asbestos I. Environmental Study, DHEW (NIOSH) Publication No. 80-115, 1980.

31 Gamble JF. A nested case control study of lung cancer among New York talc workers. Int Arch Occup Environ Health 1993;64:449-56.

32 Honda $Y$, Beall $C$, Delzell $E$, et al. Mortality among workers at a talc mining and milling facility. Ann Occup Hyg 2002;46:575-85.

33 Finkelstein MM. Malignant mesothelioma incidence among talc miners and millers in New York State. Am J Ind Med 2012;55:863-8. 